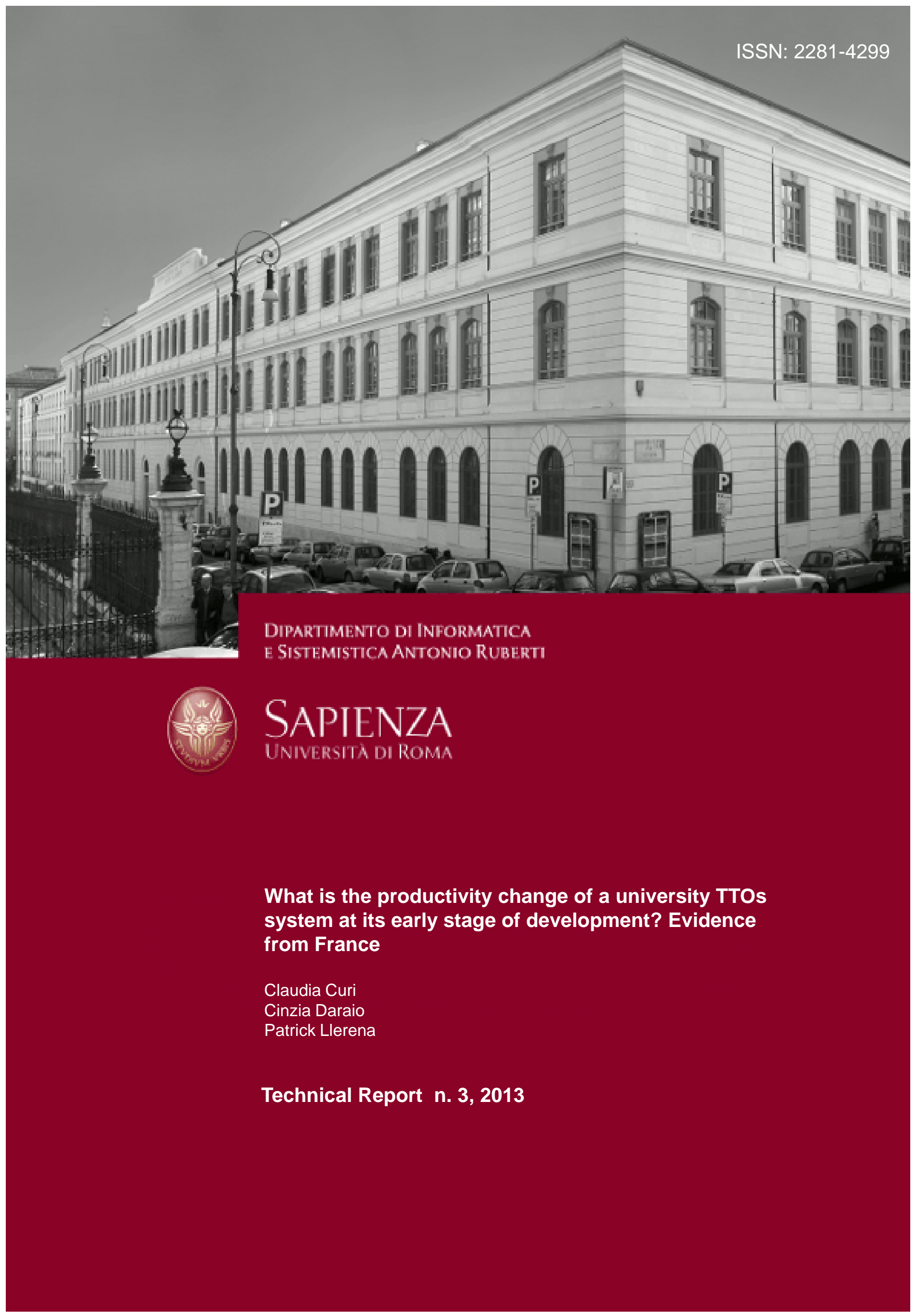




\title{
What is the productivity change of a university TTOs system at its early stage of development? Evidence from France
}

\author{
Claudia Curi ${ }^{*}$, Cinzia Daraio ${ }^{* *}$, Patrick Llerena ${ }^{* * *}$ \\ *School of Economics and Management, Free University of Bozen-Bolzano \\ ${ }^{* *}$ Department of Computer, Control and Management Engineering Antonio Ruberti, \\ University of Rome "La Sapienza" \\ ${ }^{* * *}$ University of Strasbourg, BETA (Bureau d'Economie Théorique et Appliquée) and \\ Observatoire des Sciences et Techniques (OST, Paris)
}

February, 202013

\begin{abstract}
This paper assesses the performance in technology transfer operated by the French university system adopting a Malmquist approach within an inferential setting. It investigates an original and unique database of French TTOs over their first development time. We find an overall weak increase in productivity, driven by technology and organisational improvement related to a small number of TTOs. More specifically, most TTOs show a stable innovative behaviour (i.e. no significant technical change) and only half of the system experiences a decline in efficiency change suggesting the lack of one best business model able to fit the entire system. Finally, we find that, on average, the presence of university-related hospital dampens TTOs’ efficiency and TTO's seniority has a positive effect on productivity, enhancing simultaneously efficiency and innovation.
\end{abstract}

Keywords: Technology Transfer Offices (TTOs), French University System, Malmquist Index, Data Envelopment Analysis (DEA), Bootstrap.

JEL Classification: C34; C44; D24. 


\section{Introduction}

In the current knowledge-based economy there is a general recognition of the importance of universities in producing, transferring and diffusing knowledge to the society to strengthen the so called "third mission" activity (Etzkowitz, 2002). Within this context, universities are increasingly setting up special purpose organizations in charge of technology transferring, namely the Technology Transfer Offices (TTOs). The TTOs special aim is to make feasible and effective the communication between university on one side and private firms on the other side (Pries and Guild, 2011). Although incorporated into the university structure, TTOs are subject to their own governance structures, business models and objectives.

As of today, policymakers and academics are increasingly recognizing the importance of the TTOs' intermediation role in enhancing the local and national economic development in the belief that the success of a TTO in technology transfer can result in pecuniary gains for the university and benefits for surrounding communities (Chapple et al., 2005). This has led to a considerable debate surrounding the determination of the best TTOs' business profiles, patterns of behaviour, and configurations of activities TTOs have to adopt. However, little empirical evidence has been provided on TTO’s performance (and its evolution over time), in particular for the case of European TTOs where lack and heterogeneity of data (Bonaccorsi and Daraio, 2007a,b; Daraio et al., 2011), together with a recent legislation framework, makes the entire matter much more complex.

The aim of this paper is to contribute to the current debate related to the European scenario by analysing the evolution of the productivity of a European system at its early stage of development, the French TTOs' system. The paper contributes to the current literature on TTOs performance assessment by providing the first empirical evidence of a Malmquist approach based on productivity assessment within an inferential setting. More specifically, we analyse how French TTOs perform in combining their resources (inputs) to produce the maximum feasible level of their outputs. In other terms, we assess the dynamics of TTOs productivity and analyse its main drivers: technical change (or innovation component) and efficiency change (or catching-up component). The innovation component refers to possible output mix expansions (or decreases) over time (i.e.; expansion or reduction of the technological frontier), given the resources (inputs) used, while the catching-up component refers to possible improvements (or deteriorations) of the business practices moving towards the efficient frontier (i.e. best feasible output mixes) of the sector. 
In contrast to the USA and the UK, where the technology transfer process is more advanced and the production process is more likely to run at operating speed, the French case offers an interesting laboratory where the production process is still on the way to go at full speed, and therefore characterized by continuous and sizable inputs usage but discretional output production. This kind of system deserves particular scrutiny by academics and policy decision makers as a close analysis of their operating status can provide insights useful to support further legislation adjustments the European governments might take in the near future. On the other hand, the analysis of this kind of system poses some challenges in solving issues such as process modeling, measurement accuracy, and sample selection. Moreover, the French laboratory provides a case study characterized by high level of heterogeneity among TTOs in terms of technology transferring "involvement" as it includes both research-based and more applied university categories ${ }^{1}$.

As in other countries, such as UK, the USA, Japan, and Germany (Etzkowitz, 1998; Philpott et al., 2011; Miller et al., 2012), since 1999 in France the government took steady steps to formalize university technology transfer activities (see Curi et al., 2012 for a complete description). These steps have been formalized into: “The Innovation Law”, which includes further adjustments of the previous legislative frame, and "The New Public Management Oriented Reform”. These interventions clearly enlighten the public interest in the: (i) definition (and development) of the funding scheme based on TTOs performance; (ii) identification of the key drivers of TTOs performance; (iii) and also definition of the metrics aimed at monitoring the efficiency of public spending, particularly in the science and technology field. The metrics proposed are defined in a broad sense as they include, along with patent applications, patent extensions as well as similar intellectual property rights instruments for software (Bach and Llerena, 2007).

Since the aim of our paper is to provide insights to support future policy decisions, we analyze TTOs production process by adopting the same prospective and metrics proposed by the laws (i.e. patent-related metrics), rather than develop our own output metrics. The use of such metrics is not without limitations. In fact, as the institutionalization of technology transfer is quite recent in most French universities, it appears to be very difficult to track the whole technology transfer process, including all possible technology transfer activities, for all TTOs under investigation. Moreover, a systematic and coherent information system able to record all university technology transfer activities in a comprehensive way in France does

\footnotetext{
${ }^{1}$ In this work, the university categories analysed are: (i) Engineering School, (ii) Polyvalent University with Medical School; (iii) Polyvalent University without Medical School; (iv) Science Universities.
} 
not exist. Such a context makes it difficult to find precise estimate of the relative importance of formal and informal technology transfer activities.

Summing up, we attempt to fill the gap existing in the literature by providing a first country-level assessment of productivity growth of a young system of TTOs operating in Europe based on output indicators developed by the governmental action in the early 2000s. In doing so, we complete and extend the previous analysis on the French university TTOs using a unique database available so far for the French university system (Bach and Llerena, 2008, 2010), comprehensive enough to carry out a performance assessment over time. It is worth mentioning that these are the most recent data available on the French university TTOs system given that currently the French government has stopped the annual surveys and for the moment there are not any new initiatives on this very important topic. We address the following main research questions:

1. Given previous evidence of high level of inefficiency (Curi et al. 2012), has there been an improvement of French TTOs efficiency over time or not?

2. How does the productivity of different university categories evolve over time? Do university categories show a common path to reach the frontier or does each university category show its own path? Do university categories innovate in the same way or are there different innovative categories?

As said before, French TTOs where institutionalized since 1999. However, before that some universities had already introduced "informal" internal organizations in charge of technological transferring. Thus, our sample comprises both recently established TTOs and TTOs with some history in technological transferring which are more likely to perform better. Moreover, in France there are some university categories that have a hospital as well as a hospital within their medical school. For instance, Science Universities have both medical school and university-related hospitals, while Polyvalent University may have only a medical school. Also this aspect cannot be neglected as it might influence the productivity growth assessment. Universities with related hospital carry out significant ongoing medical research whereas universities with medical school are more involved in training activity. Given these two peculiarities of the French system, we address also the following research question:

3. How do seniority and the presence of a university-related hospital influence the productivity growth of French TTOs?

We apply a frontier-based approach wherein Malmquist Productivity Index (Färe et al., 1992) and Data Envelopment Analysis (DEA) are employed. DEA is a non-parametric 
estimator of the technological frontier and determines the benchmark against which to compare the performance of each TTO. Until recently, DEA has been applied as a simple linear programming approach to obtain naïve point-estimates of TTOs efficiency scores (Thursby and Thursby, 2000; Kim, 2011), neglecting their statistical nature, i.e. without providing estimation of bias, standard deviation and confidence intervals of the estimated efficiency scores. This paper contributes to the current literature on TTO’s performance by applying for the first time productivity change assessment in an inferential setting by using the bootstrap ${ }^{2}$ (Simar and Wilson, 1999). We show the usefulness of this approach for TTOs performance assessment. It provides more accurate estimation of the efficiency scores as well as of the estimated productivity changes, revealing the statistical significance of each estimate.

The paper is organized as follows. Section 2 provides a general overview of the literature, and Section 3 describes the methodology applied. Section 4 describes the data and Section 5 discusses the main results. Section 6 concludes.

\section{A selected review of the literature}

Our analysis on French TTOs follows existing empirical studies on licensing and patenting activities (for a more general overview, see Siegel, 2007) and use the frontier approach to assess TTOs performance in terms of efficiency and productivity. As today, most of the papers focus on the analysis of TTOs' efficiency - operational and profitseeking to understand whether adjustments in TTOs production mix might improve the ability to operate and generate income and to identify the possible determinants of TTOs performance.

We count only two papers on the analysis of TTOs productivity over time. Both are based on US data, cover different time spans and use different process models. Thursby and Thursby (2002) model the technology transfer of a set of 65 US universities over the period 1994-1997 as a linear three-stage TTO’s production process (i.e.; invention disclosure is the output of the first stage, patents application is the output of the second stage, and licenses and option agreements are the outputs of third stage) and estimate the productivity related to each stage and its relative drivers ${ }^{3}$. The French TTOs’ production process has been analysed

\footnotetext{
${ }^{2}$ This is a data-based simulation method suited for statistical inference (for a more detailed explanation in the frontier context see Daraio and Simar, 2007, pp.50 ff.).

${ }^{3}$ The process starts with the first stage where invention disclosures are produced and used to fill the second stage which produces patent applications. On turn, patent applications are used as input of the third stage to produce licenses and option agreements.
} 
in Curi et al. (2012) and is comparable to the US process only in the second stage of Thursby and Thursby (2002), where patents application is the main output. With respect to the second stage, the authors find productivity growth, driven by innovation and efficiency progress.

The second paper by Kim (2011) extends the previous analysis to a sample of 90 US TTOs by tracking the year-to-year productivity growth over the period 1999-2007. He considers the technology transfer process as a whole by adopting a multi-dimensional production model and find technological change be the main driver of productivity growth. More interestingly, the author finds a high annual productivity growth rate (average value of $30 \%$ ) characterized by persistent volatility. This behavioural pattern might be ascribed to possible output production time lags which lead universities to experience large variations in productivity changes between consecutive years. In fact, the author finds that an efficient university at time $t=1$ often becomes inefficient at time $t=2$ because it is likely that the university focuses its effort on finding out new products the year after the patent release (time $t=2)$.

With regards to specific characteristics of university category, several papers (e.g.; Thursby and Kemp, 2002; Curi et al. 2012) find efficiency disparities across TTOs groups attributable to specialization of university production (such as basic research and teaching) rather than to competencies in licensing. Other papers (e.g.; Caldera and Debande, 2010) find mixed empirical evidence for the Spanish case.

It is generally assumed that universities with medical schools are likely to be more efficient than those without, because it is easier for them to conduct clinical trials and produce a large fraction of university licenses related to biomedical inventions (Curi et al., 2012). Thursby and Thursby (2002) find that the presence of a medical school acts positively on the performance of US TTOs at the invention disclosures and patent applications stages while negative at the last stage of license agreements, while Kim (2011) shows that the presence of a medical school does not by itself guarantee a high productivity in technology transfer. It is also generally assumed that a TTO could benefit from "learning by doing” experience which is directly proportional to its seniority. However, the empirical evidence shows that it might play a dual role, depending on the strategies pursued by TTO's management. Siegel et al. (2003) and Curi et al. (2012) show that older US and French TTOs, respectively, are more efficient. However, Siegel et al. (2008) find opposite results. Thursby and Thursby (2002) do not find any evidence on the importance of learning by doing. 
Table 1 summarizes the main results of nine selected studies based on both efficiency and productivity assessment that are related to the stream of literature of this paper.

Lastly, several approaches have been used to estimate efficiency in terms of distance from the efficiency frontier. Similarly to the present study, the first group includes four works based on DEA (Thursby and Kemp, 2002; Anderson et al. 2007; Kim, 2011; and Curi et al. 2012), which allow for a multi-output structure. Outputs are measured, both in terms of physical and monetary values, by the number of licences executed, invention disclosures, patent applications, and the amount of industry sponsored research and royalties received. In contrast, the second group (Siegel et al., 2003; and Chapple et al. 2005) employs a stochastic frontier estimation approach restricting the production process to one singleoutput structure but estimates two separate frontiers, one for license numbers and one for licence income, using one output at a time.

[TABLE 1 AROUND HERE]

\section{The Methodology}

We examine the productivity evolution (productivity change) through a Malmquist Productivity Index (Färe et al., 1992) approach, based on efficiency measures computed through Data Envelopment Analysis (DEA). DEA is a non-parametric estimator of the efficient frontier and determines the benchmark against which to compare the performance of each TTO. The distance of a TTO from the frontier gives its inefficiency score (Farrell, 1957). The productivity change (hereafter indicated also with $M$ which stands for Malmquist) can be decomposed in efficiency change and technical change. The efficiency change (EC) captures how close (or far) the TTOs moves to (or away) from the frontier and informs about possible catching-up. The technical change (TC) captures the shift upward (or downward) of the frontier and informs about possible new business practices in terms of additional outputs produced by TTOs. From a practical viewpoint, DEA-based Malmquist index is very useful to carry out our analysis as: (i) it does not impose any assumption on the functional form of the production frontier, (ii) it allows for simultaneous use of multiple inputs and outputs, and (iii) does not require the knowledge of price or other financial information, which are missing values for the French TTOs database we analyzed.

Until recently (see e.g. Thursby and Thursby, 2000; Kim, 2011), DEA has been applied as a simple linear programming approach to estimate efficiency scores without any statistical investigation on their significance. The novelty of this study from a methodology viewpoint is to perform the TTOs productivity assessment within an inferential setting, adopting the bootstrap procedure suggested by Simar and Wilson (1999). The crucial 
advantage of this approach is the removal of the bias from the DEA estimates and the identification of those changes which are statistically significant (at a given level of significance $\alpha \%)$.

The production model is based on the assumption that French TTOs share a common production frontier and promote the maximization of their commercial outputs, in line with the policy objective introduced by several laws (see Introduction). We compute a Malmquist output-oriented index (M) for each TTO $i$, between time $t_{1}$ and $t_{2}$, as follows:

$$
M_{i}^{t_{1}, t_{2}}=\frac{D_{i}^{t_{2}, t_{2}}}{D_{i}^{t_{1}, t_{1}}} \times\left(\frac{D_{i}^{t_{2}, t_{1}}}{D_{i}^{t_{2}, t_{2}}} \times \frac{D_{i}^{t_{1}, t_{1}}}{D_{i}^{t_{1}, t_{2}}}\right)^{0.5}=E C_{i}^{t_{1}, t_{2}} \times T C_{i}^{t_{1}, t_{2}}
$$

where $D_{i}^{t_{1}, t_{1}}=D_{i}^{t_{1}, t_{1}}\left(x_{i}^{t_{1}}, y_{i}^{t_{1}}\right)$ is the Farrell output distance (i.e. the maximum proportional expansion of the outputs given the inputs used, see Farrell, 1957) of each TTO $i$ at time $t_{1}$ relative to the technology at time $t_{1}$, and $D_{i}^{t_{1}, t_{2}}=D_{i}^{t_{1}, t_{2}}\left(x_{i}^{t_{1}}, y_{i}^{t_{1}}\right)$ is the distance relative to the technology at time $t_{2}$, while $D_{i}^{t_{2}, t_{1}}=D_{i}^{t_{2}, t_{1}}\left(x_{i}^{t_{2}}, y_{i}^{t_{2}}\right)$ and $D_{i}^{t_{2}, t_{2}}=D_{i}^{t_{2}, t_{2}}\left(x_{i}^{t_{2}}, y_{i}^{t_{2}}\right)$ are respectively the distance of each TTO at time $t_{2}$ to the technology at time $t_{1}$ and $t_{2}$. The two components of the Malmquist indices are $E C_{i}^{t_{1}, t_{2}}$ and $T C_{i}^{t_{1}, t_{2}}$ which represent the efficiency change and technological change, respectively.

$M_{i}^{t_{1}, t_{2}}, E C_{i}^{t_{1}, t_{2}}$ and $T C_{i}^{t_{1}, t_{2}}$ greater (less) than unity indicate regress (progress) between time $t_{1}$ and $t_{2}$. Values equal to unity indicate no change.

We estimate confidence intervals on EC, TC and M estimates. If a confidence interval contains the unity (that means no change), then the change turns to be not statistically significant; while if the confidence interval does not contain the unity, then the change turns to be statistically significant. Only estimates that fall in the latter case are considered in the evaluation of the productivity growth because they carry statistical significance and are not the result of sampling variation.

In Appendix A we sketch the procedure to apply the bootstrap that we followed to derive the confidence intervals on the estimated indices of $E C_{i}^{t_{1}, t_{2}}, T C_{i}^{t_{1}, t_{2}}, M_{i}^{t_{1}, t_{2}}{ }^{4}$.

\section{Data description}

Our sample consists of a balanced panel of French TTOs and it is based on data collected by BETA (Bureau d’Economie Théorique et Appliquée, UMR UdS-CNRS 7522,

\footnotetext{
${ }^{4}$ For further details see Simar and Wilson (1999).
} 
Strasbourg) with the support of the national French TTO network (CURIE), the Conference of University Rectors (CPU) and the Association of Engineering Schools Directors (CDEFI) in the years 2005 and $2007^{5}$. From a first inspection of the data, it is evident that French TTOs produce different outputs (i.e.; patent applications (PAT_APP), number of patents with submitted extension requests (PAT_EXT), number of extensions required (Nb_PAT_EXT), software applications (SW_APP)) and their production mix varies across TTOs.

Since our aim is to capture the entire production mix of French TTOs, we consider the four outputs described above and aggregated them into core and ancillary outputs. In particular, the "core output” includes patent applications as indicated by the French laws and the "ancillary output” (ANC_OUT) includes the sum of the remaining ones ${ }^{6}$. As input measures, we pick up the labour force working at the TTO, measured by the number of fulltime equivalent employees (ETP), and the stock of knowledge, measured by number of publications (PUB) ${ }^{7}$.

In addition, as a specific feature of the technology transfer process of TTOs at their early stage of development, French TTOs produce outputs at a very slow pace (i.e.; discrete output flow) while using a continuous input flow. This causes mismatching in the production process. For instance, inputs used today might produce outputs today and/or tomorrow. Having observed that, we propose a production process model assuming a "twoyear production cycle”, that is assuming two years from the starting of input usage to deliver the output. Hence, operationally, we assume that the TTO production of two consecutive years equals the yearly-based production of a regular process. This is a crude approximation of the complex reality of TTOs production process: much finer models of TTOs activity should be explored both from the theoretical and the empirical point of view. However, this is the best compromise between a workable (feasible) model of the process and the availability of data. Given that, we construct the production model as follows. On the input side, we select the average inputs used over two consecutive years, in line with previous papers (e.g.; Thursby and Kemp, 2002; Anderson et al., 2007; Curi et al., 2012) while on the output side we select the cumulative output production over two consecutive years. We end up analysing one pattern of productivity change: we compare the productivity of French TTOs in 2003-2004 to their productivity in 2005-2006.

\footnotetext{
${ }^{5}$ See Bach and Llerena (2006, 2008, 2010).

${ }^{6}$ In DEA literature, an excessive number of inputs and outputs with small samples cause the well-known "curse of dimensionality" which implies wide confidence intervals and in general imprecise results. The aggregation of outputs into two categories helps to overcome this issue.

${ }^{7}$ Elaborated by OST using Web of Science.
} 
We select only those TTOs active in the production of at least patent application activity and one of the remaining activities. TTOs with missing or invalid data as well as possible outliers are also removed from the analysis. We end up with a database of 30 TTOs covering the following university categories: (i) Engineering School (ING), (ii) Polyvalent University with Medical School (UPAM); (iii) Polyvalent University without Medical School (UPSM); (iv) Science Universities (USC). Compared to the work by Curi et al. (2012), in this study TTOs from social science and humanities, law and economics universities are removed because of their low productivity in the four selected activities in technology transfer.

Table 2 presents the summary statistics of input and output variables for sample pooled over the years 2003-2004 and 2005-2006, according to the categories of disciplinary field of the related universities. We discuss the ancillary output in its disaggregate version to better understand how French TTOs diversified their outputs during the period under analysis. These statistics enlighten the complex evolution of input usage and output production by the French system. Different patterns of growth emerge from the analysis. We can observe a general increase in SW_APP for all TTOs categories, except for UPSM. Not surprisingly there is a decrease in PAT_APP for some categories ${ }^{8}$, with the exception of ING which registers a considerable positive growth (i.e.; 18.75\%). Decrease in PAT_EXT and NB_PAT_EXT are also registered by most of university categories, expect for UPSM. Yet, in line with the expectation that French TTOs are in their early stage of development, we observe a considerable increase in the average amount of $\mathrm{ETP}^{9}$, along with a modest increase in the amount of stock of PUB.

\section{[TABLE 2 AROUND HERE]}

Not surprisingly, USC universities employ, on average, the largest amount of ETP and have the largest amount of technology stock. They seem to be very far from using similar amount of inputs used by other universities. Moreover, USC universities produce, on average, the largest amount of patent applications, as well as the largest amount of the remaining activities. ING and UPAM, on average, seem to have similar patent application production over the period 2003-2004 but not in the following period. If we look at the variability in output production within each group, evidence of it is particularly found across USC TTOs.

Summing up, it is evident that the French system exhibits a variety of outputs, which could depend on both university category and specific TTO's characteristics. These

\footnotetext{
${ }^{8}$ Namely, UPAM is the category that suffers the most (-38.21\%), followed by USC (-20.71\%) and UPSM ($18.18 \%)$.

${ }^{9}$ Namely, by category, UPSM (+63.64\%), UPAM (+56.47), ING (+35.36\%), and USC (+30.47\%).
} 
considerations show the complexity of TTOs' productivity and reinforce the use of our methodological approach rather than the use of an analysis based on simple nominal growth rate that fails to capture the multiple dimensions of TTO production. The DEA approach, on the other hand, allows us to construct the best practice frontier that is the locus where, given the level of inputs used, TTOs could not produce more as that level is the maximum achievable.

We disaggregate the results in TTOs with/without hospital and young/mature TTOs. This is to assess whether significant differences in productivity growth exist between TTOs with different intrinsic characteristics. In contrast to other studies, we do not consider the TTO's ownership (private vs. public) as all French TTOs are related to public universities. On the other hand, the TTOs' seniority, measured as the length of time that has passed since the creation of the technology transfer office, accounts for possible "learning by doing" effects in the technology transfer activity. In fact, older TTOs could benefit from their experience compared to younger TTOs. We could, thus, expect a positive impact on TTOs' efficiency if, for instance, TTOs learn to focus their strategies of technology transfer on engaging the "best" inventions to be transformed into patents, and hence producing a source of income afterward. In addition, in France, there are USC universities with both medical schools and university-related hospitals, while UPAM universities may have only the medical school. It is, therefore, more informative for the French case to control for the presence of a university-related hospital. The presence of a university-related hospital might guarantee significant ongoing medical research, whereas a simple medical school might reveal only training activity. It is usually thought that medical research is an important source of technology transfer. However, it might happen that institutions, the university and the university-related hospital, which are legally independent entities, try to capture the potential technology transfer coming from life and medical sciences. For this reason, the impact of the presence of university-related hospital is ambiguous and might depend on the competition between the two institutions (namely the university and the university-related hospital). According to the literature, in fact, results are uncertain and, for the French case, Curi et al. (2012) find that the presence of a university-related hospital is detrimental to efficiency.

Lastly, as described above, we breakdown the results by university category (i.e.; ING, UPAM, UPSM, and USC). This breakdown aims at investigating whether a catching up process between the different groups of universities exist as well as which group leads the innovation in the technology transfer. In line with the literature on efficiency analysis, we expect that the nature of disciplinary specialization of universities matters for productivity 
change but we do not know about the dynamics of catching up (or lagging-behind) of technology change.

\section{[TABLE 3 AROUND HERE]}

Table 3 shows a descriptive analysis of the variables AGE and HOSPITAL. It appears that ING (i.e.; engineering universities) are the most experienced (mean: 18.67 years) while universities UPSM (i.e.; polyvalent university without medical school) are the youngest. The presence of a hospital, in contrast, is a specific characteristic associated to UPAM and USC universities.

\section{Empirical Results}

We first present the point estimates of Malmquist indexes (M) and its relative components (EC and TC) and after their statistical significance (bias, bias-corrected estimates and confidence intervals). As described in Section 3, departing from existing literature on TTOs performance assessment, we provide a more accurate measurement by reporting information on the statistical significance of the estimated M, EC and TC. In particular, we account for the accuracy of performance assessment by looking at the width of confidence intervals. Indeed, wider confidence intervals reveal more variability in the estimation, and hence less precise point estimates.

\section{[TABLE 4 AROUND HERE]}

Table 4 shows the original point estimates and the bias-corrected estimates of productivity (and its components) of each French TTO and university category respectively. We first comment results of the entire system, then by university categories and lastly according to the university characteristics. We compute the geometric mean, including all the estimates from the sample (both statistically significant and not), as well as the geometric mean of only those estimates with statistical significance (i.e.; Geom.Mean-subset).

Based on the bias-corrected estimates, what immediately stands out is the positive productivity growth of the entire French system as a whole (measured as 1 minus the estimated productivity index $(\mathrm{M}=0.9374)$ multiplied by 100 that leads to $1-0.9374 \mathrm{x}$ $100=6.26 \%$ ). This finding is interesting because the analysis of input usage and output production (see Section 4) suggests a general increase of the former and mixed evidence of the latter, ruling out the possibility to make any expectation on the resulting multidimensional productivity. Moreover, the average productivity growth tends to be relatively consistent with the productivity growth pattern associated to each TTOs' university category, except for USC TTOs which experienced productivity decline ((1.071-1) x 100=- 
7.1\%).This is an intuitive result as USC TTOs are the only category which experienced decline in both PAT_APP and ANC_OUT.

Further, the overall productivity growth $(\mathrm{M})$ seems to be driven by changes in best practices as we observe a large positive technological change ( $\mathrm{TC}=23.99 \%$ ) compared to the negative efficiency change (EC=-15.8\%). These results are partially in line with previous findings by Thursby and Thursby (2002) as they also found a positive both technological and efficiency change for US TTOs. We cannot compare our findings with Kim's one (2011) because he investigates the US system which is at a different stage of development with respect to the French system. In fact, the analysis is carried out on universities performing at their $30^{\text {th }}$ years since the approval of the Bath-Dole Act, when presumably universities reached (or were about to reach) a more efficient stage due, at least, to learning economies.

The analysis based on TTOs category reveals the different paces at which TTOs category experienced productivity growth and sheds light on the heterogeneity of productivity growth rates. ING universities are those which experienced the largest annual growth $(\mathrm{M}=40.86 \%)$, followed by UPSM $(\mathrm{M}=27.36 \%)$ and UPAM universities with a very modest rate $(\mathrm{M}=1.9 \%)$.

What are the sources of such different productivity growth rates? The category-based decomposition reveals different evolutions of efficiency change and technological change among the different groups. In particular, the positive productivity growth rate of ING and UPSM TTOs is driven by both positive efficiency change and technical change while the modest growth of productivity of UPAM universities is driven by positive technical change but negative efficiency change. In contrast, the productivity decline of USC universities is driven by efficiency losses which are not compensated by a positive technical change. These findings have important economic implications. First, on average, early stage university TTOs drive their productivity growth by expanding their technological frontier in terms of output mix. Second, university TTOs, such as ING and UPSM universities are also able to boost their productivity growth by improving the efficiency of their business practices. On the other hand, USC and UPAM experienced difficulties in improving their practices and converging to best practices shared within their category. Given that, French TTOs show the lack of catching-up effects towards best practice business models in all TTOs categories. A catching-up convergence towards a best practice model is present only within few university categories. 
Although informative, these results require a careful interpretation as they are based only on point estimates values. Thus, as second step, we unveil additional information on the statistically significance of each of them. The analysis of their statistical significance confirms to a large extent our previous evidence of productivity growth as most TTOs (25 out of 30) experienced a statistically significant change, with the majority experiencing positive productivity growth. Only a small number of UPAM and USC TTOs showed a productivity decline. New evidence is found when efficiency and technological change are investigated within an inferential setting.

With respect to efficiency change, the French system seems likely to experience a statistically significant decrease in inefficiency at a much smaller extent, compared to the evidence previously found. Only half of the system (of which most are UPAM and USC TTOs) experienced an efficiency decline, while the remaining half did not experience any significant change. In addition, with respect to technological change, the analysis on statistical significance detects technological change at a lesser extent (compared to the evidence previously found) as only a small number of TTOs (i.e.; 7 out of 30) shows statistically significant changes, of which most are positive.

Summing up, the assessment in the inferential setting provided here offers new insights compared to the results provided by simple DEA point wise estimates. From our analysis it emerges that the French TTOs system is characterized by two sub-systems: one exhibits difficulties in improving its business practices and the other one exhibits stable behaviour with no significant changes. Second, the French TTOs system experienced difficulties in innovating, except for a small number of TTOs which push the innovation of the sector.

Thursby and Thursby (2002) point out the importance of the presence of the medical school in the commercialization process of the universities. In this study we disaggregate the performance estimates distinguishing between universities with or without a hospital ${ }^{10}$ (Table 5). French TTOs with a hospital register a decline in productivity ( $M=-4.06 \%$ ) while TTOs without hospitals appear to have a high positive productivity growth $(M=26.53)$. While the decline in productivity seems to be driven by inefficiency among TTOs with hospital, evidence of convergence to the best practices (catching-up effects) is found for the case of TTOs without hospital. Technical changes seem to be a common driver to both groups. Our findings show that the majority of TTOs without hospital did not experience any efficiency change, implying efficiency stability in their business practices, as well as

\footnotetext{
${ }^{10}$ This because in France there are Science Universities with both medical schools and university-related hospitals, while Polyvalent University with Medical School may have a medical school without a hospital (see Table 5).
} 
any technical change, implying lack of innovation. On the contrary, TTOs with hospital, on average, show a decline in their efficiency, although some of them experienced improvement in efficiency. The majority of TTOs did not experience technical changes but still a small number of TTOs with hospital (6 out of 21) experienced innovation. Overall, this evidence shows that TTOs without hospital did not significantly contribute to productivity growth, because at a large extent, show a stable pattern in both efficiency and innovation. On the other hand, TTOs with hospital contribute to the productivity growth of the French system through innovation. This finding is only partially in line with Thursby and Thursby (2002) as they find that also TTOs without medical school contribute to productivity growth.

\section{[TABLE 5 AROUND HERE]}

The last investigation is with respect to TTOs seniority (Table 6). Mature (older than 7 years old ${ }^{11}$ ) and young TTOs (younger than 7 years old) seem to perform following different patterns. While young TTOs seem to experience a decrease in productivity, mature ones tend to show an increase. Young TTOs are those suffering the most for inefficiency change while mature universities experience a modest increase in efficiency $(+2.28 \%)$. Both groups, however, experienced positive technology changes. However, the statistical analysis of efficiency results shows that most young TTOs did not experience any change in both efficiency and technical change. Only a small number experienced a high lost in efficiency and only 2 TTOs experienced innovation. On the other hand, a modest amount of mature TTOs experienced positive efficiency and technological change.

\section{[TABLE 6 AROUND HERE]}

Summing up, the French TTOs system evolves through different internal performance patterns. ING and UPSM TTOs positively contribute to the productivity growth of the system but only partially evidence of efficiency gains and innovation are found. On the other hand, performance dynamics are found more evident among UPAM and USC TTOs. Only UPAM TTOs benefit from technological change. Moreover, within TTOs with hospital, inefficiency patterns coexist with innovation pattern, while within TTOs without hospital stable patterns are found. The TTOs' age partially affects the productivity of the French TTOs system. Only a few aged TTOs contribute to the productivity growth of the French system while young TTOs do not contribute significantly to efficiency and technological change.

\footnotetext{
${ }^{11}$ We assume 7 years as the minimum age of TTOs to be considered mature.
} 
Figure 1 illustrates the distributions of DEA estimates of Malmquist index (M) efficiency change (EC) and technical change (TC) associated to each French TTO analysed; it distinguishes university categories and presence of a hospital. Looking at Figure 1, we can conclude that, with respect to efficiency change (top panel), statistically differences exist among ING, UPAM and USC TTOs, at the 5\% significant level, as shown by the lack of overlapping of the boxplots within each university category. The efficiency change distributions seem to be dispersed being located both below and above the unity. It means that differences in the performance of TTOs exist, except for UPSM TTOs which seem to perform similarly. Moreover, higher levels of dispersion are found for the most inefficient TTOs, implying the presence of a large uncertainty associated to the efficiency changes. This finding is in line with results by Curi et al. (2012) for the French case and with several authors for the US, UK and Spanish cases.

On the other hand, the empirical distributions of the estimates suggest a stable pattern of technical change, due to the overlapping of the boxplots (see middle panel of Figure 1). In addition, the system seems to be prone to innovate as the confidence intervals are distributed towards value less than one. Technical changes could be not driven by internal features, such as presence of a hospital and/or age of TTOs.

[FIGURE 1 AROUND HERE]

Figure 2 reveals other interesting aspects on the productivity dynamics. While previous results (from Figure 1) suggest that internal TTOs' features might not impact technical change, it is evident that the presence of a hospital jointly with the seniority (illustrated in Figure 2) affects the distributions of the productivity estimates. In other words, differences exist between young TTOs with hospital and the remaining TTOs (both mature and young without hospital): being a TTO with hospital does not imply to be more inefficient or be a young TTO does not imply to be more inefficient but the coexistence of these two factors possibly generate inefficiency.

These findings provide novel evidence about the patterns of productivity growth of French TTOs. Confirming results by Curi et al. (2012), according to which possible specific TTOs characteristics have a significant impact on the efficiency scores, we add evidence of a weak impact of technical changes on TTOs productivity.

[FIGURE 2 AROUND HERE] 


\section{Conclusions}

This paper is intended primarily to examine the productivity growth of a TTOs system at its early stage of development. We analyse the French university-industry technology transfer system as a specific case since major reforms happened in the early 2000s. We aim to provide new empirical evidence to support the policy debate on the drivers of TTOs efficiency growth. Empirical evidence is provided by a unique and original dataset collected by the BETA (University of Strasbourg) over the period 2003-2006. French TTOs' productivity growth is analysed by applying a DEA-based Malmquist approach framed within an inferential setting derived by applying the bootstrap technique.

In addition to previous studies, we are able to assess the statistical significance of efficiency change, technology and productivity changes. We find an overall productivity growth of about $10 \%$ for more than $80 \%$ of French TTOs. While TTOs belonging to Engineering Schools, Polyvalent Universities with Medical School, and Polyvalent Universities without Medical school contribute positively to productivity, TTOs belonging to Science Universities dampen it. Efficiency change and technical change play a different role on productivity growth. While technical change has slightly positive effects, efficiency change has shown mixed effects with more evidence of efficiency loss. Moreover, on average, the presence of university-related hospital dampens the efficiency but the lack of it does not have any significant impact. Although the presence of university-related hospital dampens the efficiency change, it simultaneously enhances innovation. We also find that TTOs seniority has a positive effect on productivity when the TTO is mature as it enhances both efficiency and technology change. Needless to say that further surveys with additional outputs (including softer channel of technology transfer activities) would be really helpful to understand the dynamics of TTOs productivity and its determinants. 


\section{Appendix}

In this section we describe the main steps to follow for estimate bias and confidence intervals on Malmquist indexes and its components.

1. Estimate the Farrell distances and compute the Malmquist Index $\hat{M}_{i}^{t_{1}, t_{2}}$ (and its relative components) defined in relation (1) by solving a DEA linear program for each TTO from the original sample;

2. Generate the pseudo-sample of inputs and outputs $\left\{\left(x_{i t}^{*}, y_{i t}^{*}\right) \mid i=1, \ldots, N ; t=1,2\right\}$ by adopting the smooth bootstrap procedure based on bivariate kernel density (to preserve temporal correlation in the data), along with the reflection method (Silverman, 1986) adapted to the bivariate case. This consists of randomly drawing with replacement the distances from $4 \mathrm{~N}$ unbounded observations, where the smoothing parameter is selected following the normal rule of thumb, that is $h=(4 / 5 N)^{1 / 6}$;

3. Estimate the Malmquist index $\hat{M}_{i, b^{*}}^{t_{1}, t_{2}}$ (and its relative components) from the pseudosample obtained in step 2 for each TTO;

4. Repeat steps 2 and 3 a number of bootstrap replications ( $B, B$ could be for instance 200) in order to provide a enough large set of estimates for Malmquist index $\left\{\hat{M}_{i, b^{*}}^{t_{1}, t_{2}}, \ldots, \hat{M}_{i, B^{*}}^{t_{1}, t_{2}}\right\}$ and each components of relation (1).

5. For each Malquist index (and components), calculate the specific bias-correction term and the confidence intervals by selecting the appropriate percentile.

The bias-corrected estimate of the Malmquist Index is computed as: $\hat{M}_{i, b c}^{t_{1}, t_{2}}=\hat{M}_{i}^{t_{1}, t_{2}}-b i a s_{i}=2 \hat{M}_{i}^{t, t_{2}}-B^{-1} \sum_{b=1}^{B} \hat{M}_{i, b^{*}}^{t, t_{2}}, i=1, \ldots, N$

where $b=1, \ldots, B$ is the number of replications, and the bias is:

biâs $_{i}=B^{-1} \sum_{b=1}^{B} \hat{M}_{i, b^{*}}^{t_{1}, t_{2}}-\hat{M}_{i}^{t_{1}, t_{2}} \quad i=1, \ldots, N$

The idea beyond the construction of the confidence intervals is based on the approximation of the unknown distribution $\hat{M}_{i}^{t_{1}, t_{2}}-M_{i}^{t_{1}, t_{2}}$ by the distribution $\hat{M}_{i, b^{*}}^{t_{1}, t_{2}}-\hat{M}_{i}^{t_{1}, t_{2}}$, conditioned to the original sample data of inputs and outputs. We build confidence intervals by sorting the values $\left\{\hat{M}_{i, b^{2}}^{t_{1} t_{2}}-\hat{M}_{i}^{t_{1}, t_{2}}\right\}_{b=1}^{B}$ in increasing order and delete $((\alpha / 2) x 100)$-percent of the elements at either end of the sorted list. The estimated $(1-\alpha)$-percent confidence interval for the Malmquist index of each TTO is then: 


$$
\hat{M}_{i}^{t_{1}, t_{2}}+\hat{a}_{\alpha}^{*} \leq M_{i}^{t_{1}, t_{2}} \leq \hat{M}_{i}^{t_{1}, t_{2}}+\hat{b}_{\alpha}^{*}
$$

where $-\hat{a}_{\alpha}^{*}$ and $-\hat{b}_{\alpha}^{*}$ are the endpoints of the sorted array, with $\hat{a}_{\alpha}^{*} \prec \hat{b}_{\alpha}^{*}$.

Relations (2) and (4) are similarly computed for the two components of the Malmquist Index: efficiency change and technological change. 


\section{References}

Anderson, T.R., Daim, T.U., Lavoie, F.F., 2007. Measuring the efficiency of university technology transfer. Technovation 27, 306-318.

Bach L. and Llerena, P., 2006. Les activités de recherche contractuelle et de transfert de technologie dans les établissements français d'enseignement supérieur, Rapport Final, L. Bach, P. Llerena, pour le Ministère de l'Enseignement Supérieur et de la Recherche (MESR), Paris.

Bach L. and Llerena, P., 2007. Indicators of higher-education institutes and public-research organizations technology transfer activities: insights from France, Science and Public Policy 34 (10), 709-721.

Bach L., Llerena P., 2008. Les activités de recherche contractuelle et de transfert de technologie dans les établissements français d’enseignement supérieur, Rapport Final, L. Bach, P. Llerena, pour le Ministère de l’Enseignement Supérieur et de la Recherche (MESR), Paris.

Bach L., Llerena P., 2010. Les activités de recherche contractuelle et de transfert de technologie dans les établissements français d’enseignement supérieur, Rapport Final, L. Bach, P. Llerena, pour le Ministère de l'Enseignement Supérieur et de la Recherche (MESR), Paris.

Bonaccorsi A., Daraio C., 2007a. Theoretical perspectives on university strategy, in Bonaccorsi A., Daraio C. (2007), Eds, Universities and strategic knowledge creation. Specialization and performance in Europe, Edward Elgar, Cheltenham, pp. 3-30.

Bonaccorsi A. Daraio C., 2007b. Universities as strategic knowledge creators. Some preliminary evidence, in Bonaccorsi A., Daraio C. (2007), Eds, Universities and strategic knowledge creation. Specialization and performance in Europe, Edward Elgar, Cheltenham, pp. 31-84.

Caldera, A., Debande, O., 2010. Performance of Spanish universities in technology transfer: An empirical analysis. Research Policy 39 (9), 1160-1173.

Chapple, W., Lockett, A., Siegel, D.S., Wright, M., 2005. Assessing the relative performance of university technology transfer office in UK: parametric and nonparametric evidence. Research Policy 34 (3), 369-284.

Curi, C., Daraio, C., Llerena P., 2012, University technology transfer: how (in)efficient are French universities? Cambridge Journal of Economics 36 (3), 629-654.

Daraio, C. et al., 2011. The European University landscape: A micro characterization based on evidence from the Aquameth project. Research Policy 40, 148-164. 
Daraio, C., Simar L., 2007. Advanced Robust and Nonparametric Methods in Efficiency Analysis. Methodology and Applications, Springer, New York.

Etzkovitz, H., 2002. Incubation of incubators: innovation as a triple helix of universityindustry-government networks. Science and Public Policy 29, 115-128.

Färe, R., Grosskopf, S., Norris, M., Zhang, Z., 1994. Productivity growth, technical progress and efficiency change in industrialized countries. American Economic Review 84, 6683.

Farrell, M.J., 1957. The measurement of productive efficiency, Journal of the Royal Statistical Society Series A 1 (20), 253-281.

Miller, K., McAdam, M., McAdam, R., Teague, S., 2012. The Development of University Technology Transfer Stakeholder Relationships at a Regional Level: Lessons for the Future. Technovation 32 (1), 57-67.

Kim, Y., 2011. The ivory tower approach to entrepreneurial linkage: productivity changes in university technology transfer. Journal of Technology Transfer, DOI: 10.1007/s10961011-9217-8.

OST 2006, 2008, 2010. Rapport de l’Observatoire des Sciences et des Techniques, Economia, Paris, Editions 2006, 2008 and 2010.

Philpott, K., Dooley, L., O’Reilly, C., Lupton, G., 2011. The entrepreneurial university: Examining the underlying academic tension. Technovation 32, 161-170.

Pries, F., Guild, P., 2011. Commercializing inventions resulting from university research: Analyzing the impact of technology characteristics on subsequent business models. Technovation 31 (4), 151-160.

Siegel, D., Waldman, D., Link, A., 2003. Assessing the impact of organizational practices on the relative productivity of university technology transfer offices: an exploratory study. Research Policy 32, 27-48.

Siegel, D., 2007. Technology transfer offices and commercialization of university intellectual property: performance and policy implications. Oxford Review of Economic Policy 23 (4), 640-660.

Siegel, D., Wright, M., Chapple, W., Lockett, A., 2008. Assessing the relative performance of university technology transfer in the US and IK: a stochastic distance function approach. Economics of Innovation and New Technology 17, 717-729.

Simar, L., Wilson, P.W., 1999. Estimating and bootstrapping Malmquist indices. European Journal of Operational Research 115, 459-471. 
Thursby, J. G., Thursby, M. C., 2002. Who is selling the Ivory Tower? Sources of Growth in University Licensing. Management Science 48 (1), 90-104.

Thursby, J. G., Kemp, S., 2002. Growth and Productive Efficiency of University Intellectual Property Licensing. Research Policy 31, 109-124. 
Tables of the paper

Table 1: Selected results from the literature on TTOs' efficiency and productivity

\begin{tabular}{|c|c|c|c|c|c|c|c|}
\hline TTOs & Number of outputs & Authors & Output used & MED & AGE & PUB & GROUP $^{\mathrm{a}}$ \\
\hline \multicolumn{8}{|c|}{ Efficiency analysis } \\
\hline France & Multiple & Curi et al. 2012 & $\begin{array}{l}\text { Patent applications,software applications, } \\
\text { patents with submitted extension requests, } \\
\text { number of extension required }\end{array}$ & - & + & & yes \\
\hline \multirow[t]{4}{*}{ USA } & One & Siegel et al. 2003 & Number of licenses & & & & \\
\hline & & $\begin{array}{l}\text { Anderson et al. } \\
2007\end{array}$ & & ne & ne & ne & \\
\hline & & & Licensing income & ne & + & ne & \\
\hline & Multiple & $\begin{array}{l}\text { Thursby and Kemp } \\
2002\end{array}$ & $\begin{array}{l}\text { Number of licenses, patent applications, } \\
\text { invention disclosures, amount of royalties and } \\
\text { industry sponsored research }\end{array}$ & - & & $+^{\mathrm{b}}$ & yes \\
\hline \multirow[t]{2}{*}{ UK } & One & Chapple et al. 2005 & Number of licenses & ne & + & & \\
\hline & & & Licensing Income & - & ne & & \\
\hline \multirow[t]{2}{*}{ Spain } & One & $\begin{array}{l}\text { Caldera and } \\
\text { Debande } 2010\end{array}$ & Number of licenses & ne & ne & - & ne \\
\hline & & & Licensing Income & ne & + & ne & + \\
\hline $\begin{array}{l}\text { US \& } \\
\text { UK }\end{array}$ & Multiple & Siegel et al. 2008 & $\begin{array}{l}\text { Number of licenses, income from licenses, } \\
\text { university start-ups }\end{array}$ & + & - & & \\
\hline \multicolumn{8}{|c|}{ Productivity analysis } \\
\hline USA & One & $\begin{array}{l}\text { Thursby and } \\
\text { Thursby } 2002\end{array}$ & $\begin{array}{l}\text { Investion Discolures, Patent Applications, } \\
\text { Licenses Executed }\end{array}$ & + & ne & & \\
\hline & Multiple & Kim 2012 & $\begin{array}{l}\text { Number of Patents, Number of licenses, } \\
\text { License Income }\end{array}$ & ne & & & \\
\hline
\end{tabular}

MED, medical school; AGE, TTO age; PUB, public university; GROUP, group characteristics.

Notes: 'ne' indicates no effect; '+' indicates positive effects; '-' indicates negative effects; and 'yes' indicates that there is an impact and it depends on what we control for.

${ }^{\mathrm{a}}$ This effect is controlled using different approaches.

${ }^{\mathrm{b}}$ In this case, the authors test whether (or not) a private university effects TTO performance. 


\section{Table 2: Descriptive Statistics by university categories}

\begin{tabular}{|c|c|c|c|c|c|c|c|c|c|c|c|c|c|}
\hline $\begin{array}{l}\text { University } \\
\text { category }\end{array}$ & Statistics & ETP & PUB & PAT_APP & SW_APP & PAT_EXT & Nb_PAT_EXT & ETP & PUB & PAT_APP & SW_APP & PAT_EXT & Nb_PAT_EXT \\
\hline \multirow{5}{*}{ ING } & & \multicolumn{6}{|c|}{ 2003-2004 } & \multicolumn{6}{|c|}{$2005-2006$} \\
\hline & Mean & 4.67 & 1888.33 & 10.67 & 0.67 & 3.33 & 6.00 & 6.32 & 2139.67 & 12.67 & 2.33 & 1.33 & 1.33 \\
\hline & SD & 4.62 & 723.78 & 9.50 & 1.15 & 4.16 & 4.00 & 4.04 & 787.75 & 6.51 & 1.53 & 2.31 & 2.31 \\
\hline & Min & 2.00 & 1420.50 & 1.00 & 0.00 & 0.00 & 2.00 & 2.00 & 1615.00 & 6.00 & 1.00 & 0.00 & 0.00 \\
\hline & Max & 10.00 & 2722.00 & 20.00 & 2.00 & 8.00 & 10.00 & 10.00 & 3045.50 & 19.00 & 4.00 & 4.00 & 4.00 \\
\hline \multirow[t]{4}{*}{ UPAM } & Mean & 3.38 & 1487.08 & 10.25 & 1.00 & 4.42 & 4.83 & 5.29 & 1468.67 & 6.33 & 2.42 & 1.50 & 1.58 \\
\hline & SD & 1.06 & 647.51 & 7.94 & 1.48 & 4.38 & 4.43 & 3.89 & 647.47 & 4.16 & 2.43 & 1.68 & 1.62 \\
\hline & Min & 1.50 & 757.50 & 2.00 & 0.00 & 0.00 & 0.00 & 1.90 & 481.00 & 1.00 & 0.00 & 0.00 & 0.00 \\
\hline & Max & 5.00 & 2849.00 & 24.00 & 5.00 & 12.00 & 13.00 & 15.58 & 2891.50 & 15.00 & 7.00 & 5.00 & 5.00 \\
\hline \multirow[t]{4}{*}{ UPSM } & Mean & 1.83 & 920.00 & 7.33 & 1.33 & 0.67 & 2.67 & 3.00 & 952.17 & 6.00 & 1.00 & 3.33 & 3.33 \\
\hline & SD & 1.04 & 1181.02 & 7.51 & 1.15 & 1.15 & 1.15 & 0.66 & 1176.28 & 5.29 & 1.00 & 3.51 & 3.51 \\
\hline & Min & 1.00 & 137.50 & 3.00 & 0.00 & 0.00 & 2.00 & 2.25 & 175.50 & 2.00 & 0.00 & 0.00 & 0.00 \\
\hline & Max & 3.00 & 2278.50 & 16.00 & 2.00 & 2.00 & 4.00 & 3.50 & 2305.50 & 12.00 & 2.00 & 7.00 & 7.00 \\
\hline \multirow[t]{4}{*}{ USC } & Mean & 10.19 & 6082.13 & 23.33 & 3.33 & 14.83 & 15.75 & 13.29 & 6569.75 & 18.50 & 3.67 & 5.17 & 6.75 \\
\hline & SD & 7.05 & 3799.23 & 12.40 & 5.03 & 9.24 & 8.80 & 7.75 & 4166.86 & 14.98 & 5.09 & 6.28 & 5.69 \\
\hline & Min & 4.00 & 2063.00 & 7.00 & 0.00 & 3.00 & 5.00 & 3.00 & 2141.50 & 2.00 & 0.00 & 0.00 & 0.00 \\
\hline & Max & 30.00 & 15422.00 & 43.00 & 17.00 & 34.00 & 33.00 & 34.10 & 17160.50 & 52.00 & 17.00 & 18.00 & 18.00 \\
\hline
\end{tabular}

Source: Authors' calculations 
Table 3: Descriptive Statistics by university categories of universities

\begin{tabular}{|c|c|c|c|c|c|c|}
\hline $\begin{array}{l}\text { University } \\
\text { Category }\end{array}$ & Variable & N.Obs & Mean & SD & Min & Max \\
\hline \multirow[t]{3}{*}{ ING } & & 3 & & & & \\
\hline & Hospital & & 0.00 & 0.00 & 0.00 & 0.00 \\
\hline & Age & & 18.67 & 8.50 & 10.00 & 27.00 \\
\hline \multirow[t]{3}{*}{ UPAM } & & 12 & & & & \\
\hline & Hospital & & 0.92 & 0.29 & 0.00 & 1.00 \\
\hline & Age & & 9.25 & 2.73 & 5.00 & 13.00 \\
\hline \multirow[t]{3}{*}{ UPSM } & & 3 & & & & \\
\hline & Hospital & & 0.00 & 0.00 & 0.00 & 0.00 \\
\hline & Age & & 3.33 & 0.58 & 3.00 & 4.00 \\
\hline \multirow[t]{3}{*}{ USC } & & 12 & & & & \\
\hline & Hospital & & 0.83 & 0.39 & 0.00 & 1.00 \\
\hline & Age & & 16.08 & 9.22 & 3.00 & 36.00 \\
\hline
\end{tabular}


Table 4: Summary of results for the French TTOs between 2003 and 2006 by university category

\begin{tabular}{|c|c|c|c|c|c|c|}
\hline University Category & EC & BC-EC & TC & BC-TC & M & BC-M \\
\hline ING-9 & 1.1793 & 1.3281 & 0.8675 & $0.7175 * *$ & 1.0231 & 1.0207 \\
\hline ING-24 & 0.2829 & $0.2943^{* *}$ & 0.8968 & 0.7821 & 0.2537 & $0.2379 * *$ \\
\hline ING-30 & 0.9139 & 0.9527 & 0.9520 & 0.8656 & 0.8701 & $0.8516^{* *}$ \\
\hline Geom.Mean-all & 0.6731 & 0.7194 & 0.9048 & 0.7861 & 0.6090 & 0.5914 \\
\hline Geom.Mean-subset & 0.2829 & 0.2943 & 0.8675 & 0.7175 & 0.4699 & 0.4501 \\
\hline Improvement & & 1 & & 1 & & 2 \\
\hline No change & & 2 & & 2 & & 1 \\
\hline Decline & & 0 & & 0 & & 0 \\
\hline UPAM-2 & 1.0872 & 1.2904 & 0.8102 & 0.7268 & 0.8809 & 1.0082 \\
\hline UPAM-14 & 1.0000 & 1.1315 & 0.9428 & 0.7629 & 0.9428 & $0.9423 * *$ \\
\hline UPAM-18 & 0.6788 & $0.7327 * *$ & 0.8254 & $0.6898 * *$ & 0.5602 & $0.5361^{* *}$ \\
\hline UPAM-21 & 1.4732 & $1.6565^{* *}$ & 0.8355 & $0.7277 * *$ & 1.2308 & $1.2763^{* *}$ \\
\hline UPAM-22 & 1.0000 & 1.0056 & 0.9769 & 0.8924 & 0.9769 & 0.9226 \\
\hline UPMA-23 & 1.4461 & 1.5123 & 0.9383 & 0.7959 & 1.3569 & $1.2790 * *$ \\
\hline UPAM-31 & 3.8195 & $4.4114^{* *}$ & 0.8680 & $0.7292 * *$ & 3.3155 & $3.4756^{* *}$ \\
\hline UPAM-41 & 4.1658 & $4.5513^{* *}$ & 0.9315 & 0.8139 & 3.8804 & $3.8962 * *$ \\
\hline UPAM-43 & 0.3163 & $0.3351^{* *}$ & 0.8659 & 0.7727 & 0.2739 & $0.2722 * *$ \\
\hline UPAM-50 & 0.7734 & 0.8461 & 0.8565 & $0.7331 * *$ & 0.6624 & $0.6522 * *$ \\
\hline UPAM-55 & 0.3873 & $0.4265 * *$ & 0.8549 & $0.7326 * *$ & 0.3311 & $0.3311^{* *}$ \\
\hline UPAM-59 & 1.5407 & $1.5880^{* *}$ & 0.9012 & 0.7943 & 1.3884 & 1.3007 \\
\hline Geom.Mean-all & 1.1140 & 1.2154 & 0.8825 & 0.7626 & 0.9830 & 0.9810 \\
\hline Geom.Mean-subset & 1.1701 & 1.2768 & 0.8479 & 0.7223 & 0.9583 & 0.9543 \\
\hline Improvement & & 3 & & 5 & & 5 \\
\hline No change & & 5 & & 7 & & 3 \\
\hline Decline & & 4 & & 0 & & 4 \\
\hline UPSM-4 & 1.0000 & 1.0489 & 0.8462 & 0.7265 & 0.8462 & $0.8556 * *$ \\
\hline UPSM-17 & 0.6611 & 0.8756 & 0.7114 & $0.4994 * *$ & 0.4703 & $0.5514 * *$ \\
\hline UPSM-25 & 0.8363 & 1.0300 & 0.8747 & 0.7068 & 0.7315 & $0.8123^{* *}$ \\
\hline Geom.Mean-all & 0.8208 & 0.9816 & 0.8075 & 0.6353 & 0.6627 & 0.7264 \\
\hline Geom.Mean-subset & 0.0000 & 0.0000 & 0.7114 & 0.4994 & 0.6627 & 0.7264 \\
\hline Improvement & & 0 & & 1 & & 3 \\
\hline No change & & 3 & & 2 & & 0 \\
\hline Decline & & 0 & & 0 & & 0 \\
\hline USC-5 & 2.3667 & $2.5271^{* *}$ & 0.8824 & 0.7747 & 2.0883 & $2.0241 * *$ \\
\hline USC-13 & 4.5179 & $4.8508 * *$ & 0.9615 & 0.8372 & 4.3440 & $4.2390 * *$ \\
\hline USC-26 & 0.6563 & $0.7150 * *$ & 0.9059 & 0.7557 & 0.5945 & $0.5831 * *$ \\
\hline USC-33 & 0.7514 & 0.8142 & 0.9380 & 0.8600 & 0.7049 & $0.7225^{* *}$ \\
\hline USC-37 & 1.5389 & $1.6344^{* *}$ & 0.8784 & 0.7292 & 1.3517 & $1.2669 * *$ \\
\hline USC-42 & 2.6964 & $2.9344^{* *}$ & 0.9691 & 0.8190 & 2.6130 & $2.5498 * *$ \\
\hline USC-51 & 1.3346 & 1.4774 & 0.8783 & 0.7472 & 1.1721 & $1.1800^{* *}$ \\
\hline USC-64 & 1.5187 & 1.6225 & 0.8604 & 0.7357 & 1.3067 & 1.2582 \\
\hline USC-65 & 0.6730 & $0.6975^{* *}$ & 0.9234 & 0.8080 & 0.6215 & $0.5855^{* *}$ \\
\hline USC-68 & 0.7268 & $0.7412^{* *}$ & 0.9955 & 0.8866 & 0.7236 & $0.6809 * *$ \\
\hline USC-69 & 0.8956 & 0.9304 & 0.8896 & 0.7280 & 0.7967 & $0.7192 * *$ \\
\hline USC-73 & 0.5235 & $0.5659 * *$ & 0.9211 & 0.7673 & 0.4822 & $0.4598 * *$ \\
\hline
\end{tabular}




\begin{tabular}{lclllll}
\hline University Category & EC & BC-EC & TC & BC-TC & M & BC-M \\
\hline Geom.Mean-all & 1.2132 & 1.2954 & 0.9161 & 0.7857 & 1.1114 & 1.0713 \\
Geom.Mean-subset & 1.2855 & 1.3684 & 0.8824 & 0.7747 & 1.0952 & 1.0558 \\
Improvement & & 4 & & 0 & 6 \\
No change & & 4 & & 12 & 1 \\
Decline & & 4 & & 0 & 5 \\
\hline Geom.Mean-all & 1.0631 & 1.1581 & 0.8901 & 0.7601 & 0.9462 & 0.9374 \\
Geom.Mean-subset & 1.1223 & 1.2060 & 0.8296 & 0.6846 & 0.9184 & 0.9092 \\
Improvement & & 8 & & 7 & 16 \\
No change & & 14 & & 23 & 5 \\
Decline & & 8 & & 0 & & 9 \\
\hline
\end{tabular}

$\mathrm{EC}=$ Efficiency Change, $\mathrm{TC}=$ Technical Change, $\mathrm{M}=$ Malmquist index. $\mathrm{BC}-=$ Bias-Corrected. ${ }^{* *}$ statistically significant at 5\%. Notes: Geom.Mean-all is calculated as the mean of changes associated to the entire sample whereas Geom.Mean-subset is calculated as the mean of only statistically significant changes. Improvement, No change and Decline indicate the number of TTOs which experienced statistically significant progress, any significant change, and statistically significant regress, respectively.

Table 5: Summary of results for the French TTOs between 2003 and 2006, depending on the presence of a hospital

\begin{tabular}{llllllll}
\hline Hospital & University Category & EC & BC-EC & TC & BC-TC & M & BC-M \\
\hline Yes & UPAM-2 & 1.0872 & 1.2904 & 0.8102 & 0.7268 & 0.8809 & 1.0082 \\
Yes & USC-5 & 2.3667 & $2.5271^{* *}$ & 0.8824 & $0.7747^{* *}$ & 2.0883 & $2.0241^{* *}$ \\
Yes & USC-13 & 4.5179 & $4.8508^{* *}$ & 0.9615 & 0.8372 & 4.3440 & $4.2390^{* *}$ \\
Yes & UPAM-14 & 1.0000 & 1.1315 & 0.9428 & 0.7629 & 0.9428 & $0.9423^{* *}$ \\
Yes & UPAM-18 & 0.6788 & $0.7327^{* *}$ & 0.8254 & $0.6898^{* *}$ & 0.5602 & $0.5361^{* *}$ \\
Yes & UPAM-21 & 1.4732 & $1.6565^{* *}$ & 0.8355 & $0.7277^{* *}$ & 1.2308 & $1.2763^{* *}$ \\
Yes & UPAM-23 & 1.4461 & 1.5123 & 0.9383 & 0.7959 & 1.3569 & $1.2790^{* *}$ \\
Yes & USC-26 & 0.6563 & $0.7150^{* *}$ & 0.9059 & 0.7557 & 0.5945 & $0.5831^{* *}$ \\
Yes & UPAM-31 & 3.8195 & $4.4114^{* *}$ & 0.8680 & $0.7292^{* *}$ & 3.3155 & $3.4756^{* *}$ \\
Yes & USC-37 & 1.5389 & $1.6344^{* *}$ & 0.8784 & 0.7292 & 1.3517 & $1.2669^{* *}$ \\
Yes & UPAM-41 & 4.1658 & $4.5513^{* *}$ & 0.9315 & 0.8139 & 3.8804 & $3.8962^{* *}$ \\
Yes & USC-42 & 2.6964 & $2.9344^{* *}$ & 0.9691 & 0.8190 & 2.6130 & $2.5498^{* *}$ \\
Yes & UPAM-43 & 0.3163 & $0.3351^{* *}$ & 0.8659 & 0.7727 & 0.2739 & $0.2722^{* *}$ \\
Yes & UPAM-50 & 0.7734 & 0.8461 & 0.8565 & $0.7331^{* *}$ & 0.6624 & $0.6522^{* *}$ \\
Yes & UPAM-55 & 0.3873 & $0.4265^{* *}$ & 0.8549 & $0.7326^{* *}$ & 0.3311 & $0.3311^{* *}$ \\
Yes & UPAM-59 & 1.5407 & $1.5880^{* *}$ & 0.9012 & 0.7943 & 1.3884 & 1.3007 \\
Yes & USC-64 & 1.5187 & 1.6225 & 0.8604 & 0.7357 & 1.3067 & 1.2582 \\
Yes & USC-65 & 0.6730 & $0.6975^{* *}$ & 0.9234 & 0.8080 & 0.6215 & $0.5855^{* *}$ \\
Yes & USC-68 & 0.7268 & $0.7412^{* *}$ & 0.9955 & 0.8866 & 0.7236 & $0.6809^{* *}$ \\
Yes & USC-69 & 0.8956 & 0.9304 & 0.8896 & 0.7280 & 0.7967 & $0.7192^{* *}$ \\
Yes & USC-73 & 0.5235 & $0.5659^{* *}$ & 0.9211 & 0.7673 & 0.4822 & $0.4598^{* *}$ \\
Geom.Mean-all & & 1.1877 & 1.2844 & 0.8948 & 0.7663 & 1.0627 & 1.0406 \\
Geom.Mean-subset & & 1.2303 & 1.3249 & 0.8536 & 0.7308 & 1.0459 & 1.0188 \\
Improvement & & & 7 & & 6 & & 10 \\
No change & & 6 & & 15 & & 3 \\
Decline & & 8 & & 0 & & 8
\end{tabular}




\begin{tabular}{llllllll}
\hline Hospital & University Category & EC & BC-EC & TC & BC-TC & M & BC-M \\
\hline No & UPSM-4 & 1.0000 & 1.0489 & 0.8462 & 0.7265 & 0.8462 & $0.8556^{* *}$ \\
No & ING-9 & 1.1793 & 1.3281 & 0.8675 & $0.7175^{* *}$ & 1.0231 & 1.0207 \\
No & UPSM-17 & 0.6611 & 0.8756 & 0.7114 & $0.4994^{* *}$ & 0.4703 & $0.5514^{* *}$ \\
No & UPAM-22 & 1.0000 & 1.0056 & 0.9769 & 0.8924 & 0.9769 & 0.9226 \\
No & ING-24 & 0.2829 & $0.2943^{* *}$ & 0.8968 & 0.7821 & 0.2537 & $0.2379^{* *}$ \\
No & UPSM-25 & 0.8363 & 1.0300 & 0.8747 & 0.7068 & 0.7315 & $0.8123^{* *}$ \\
No & ING-30 & 0.9139 & 0.9527 & 0.9520 & 0.8656 & 0.8701 & $0.8516^{* *}$ \\
No & USC-33 & 0.7514 & 0.8142 & 0.9380 & 0.8600 & 0.7049 & $0.7225^{* *}$ \\
No & USC-51 & 1.3346 & 1.4774 & 0.8783 & 0.7472 & 1.1721 & $1.1800^{* *}$ \\
Geom.Mean-all & & 0.8208 & 0.9095 & 0.8792 & 0.7459 & 0.7216 & 0.7347 \\
Geom.Mean-subset & & 0.2829 & 0.2943 & 0.7856 & 0.5986 & 0.6575 & 0.6785 \\
Improvement & & & 0 & & 2 & & 6 \\
No change & & 8 & & 7 & & 2 \\
Decline & & & 1 & & 0 & & 1 \\
\hline
\end{tabular}

EC= Efficiency Change, TC=Technical Change, $\mathrm{M}=$ Malmquist index. BC-=Bias-Corrected. ** statistically significant at 5\%. Notes: Geom.Mean-all is calculated as the mean of changes associated to the entire sample whereas Geom.Mean-subset is calculated as the mean of only statistically significant changes. Improvement, No change and Decline indicate the number of TTOs which experienced statistically significant progress, any significant change, and statistically significant regress, respectively.

Table 6: Summary of results for the French TTOs between 2003 and 2006, by age

\begin{tabular}{llllllll}
\hline Young TTO & University Category & EC & BC-EC & TC & BC-TC & M & BC-M \\
\hline Yes & UPSM-4 & 1.0000 & 1.0489 & 0.8462 & 0.7265 & 0.8462 & $0.8556^{* *}$ \\
Yes & USC-13 & 4.5179 & $4.8508^{* *}$ & 0.9615 & 0.8372 & 4.3440 & $4.2390^{* *}$ \\
Yes & UPSM-17 & 0.6611 & 0.8756 & 0.7114 & $0.4994^{* *}$ & 0.4703 & $0.5514^{* *}$ \\
Yes & UPAM-22 & 1.0000 & 1.0056 & 0.9769 & 0.8924 & 0.9769 & 0.9226 \\
Yes & UPAM-23 & 1.4461 & 1.5123 & 0.9383 & 0.7959 & 1.3569 & $1.2790^{* *}$ \\
Yes & UPSM-25 & 0.8363 & 1.0300 & 0.8747 & 0.7068 & 0.7315 & $0.8123^{* *}$ \\
Yes & UPAM-31 & 3.8195 & $4.4114^{* *}$ & 0.8680 & $0.7292^{* *}$ & 3.3155 & $3.4756^{* *}$ \\
Yes & USC-37 & 1.5389 & $1.6344^{* *}$ & 0.8784 & 0.7292 & 1.3517 & $1.2669^{* *}$ \\
Yes & UPAM-41 & 4.1658 & $4.5513^{* *}$ & 0.9315 & 0.8139 & 3.8804 & $3.8962^{* *}$ \\
Yes & USC-73 & 0.5235 & $0.5659^{* *}$ & 0.9211 & 0.7673 & 0.4822 & $0.4598^{* *}$ \\
Geom.Mean-all & & 1.4674 & 1.6265 & 0.8876 & 0.7421 & 1.3025 & 1.3121 \\
Geom.Mean-subset & & 2.2519 & 2.4599 & 0.7858 & 0.6035 & 1.3448 & 1.3644 \\
Improvement & & & 1 & & 2 & & 4 \\
No change & & & 5 & & 8 & & 1 \\
Decline & & & 4 & & 0 & & 5 \\
No & & 1.0872 & 1.2904 & 0.8102 & 0.7268 & 0.8809 & 1.0082 \\
No & UPAM-2 & 2.3667 & $2.5271^{* *}$ & 0.8824 & 0.7747 & 2.0883 & $2.0241^{* *}$ \\
No & USC-5 & 1.1793 & 1.3281 & 0.8675 & $0.7175^{* *}$ & 1.0231 & 1.0207 \\
No & ING-9 & 1.0000 & 1.1315 & 0.9428 & 0.7629 & 0.9428 & $0.9423^{* *}$ \\
No & UPAM-14 & 0.6788 & $0.7327^{* *}$ & 0.8254 & $0.6898^{* *}$ & 0.5602 & $0.5361^{* *}$ \\
No & UPAM-18 & 1.4732 & $1.6565^{* *}$ & 0.8355 & $0.7277 * *$ & 1.2308 & $1.2763^{* *}$ \\
No & UPAM-21 & 0.2829 & $0.2943^{* *}$ & 0.8968 & 0.7821 & 0.2537 & $0.2379^{* *}$ \\
No & ING-24 & 0.6563 & $0.7150^{* *}$ & 0.9059 & 0.7557 & 0.5945 & $0.5831^{* *}$ \\
& USC-26 & & & & & &
\end{tabular}




\begin{tabular}{llllllll}
\hline Young TTO & University Category & EC & BC-EC & TC & BC-TC & M & BC-M \\
\hline No & ING-30 & 0.9139 & 0.9527 & 0.9520 & 0.8656 & 0.8701 & $0.8516^{* *}$ \\
No & USC-33 & 0.7514 & 0.8142 & 0.9380 & 0.8600 & 0.7049 & $0.7225^{* *}$ \\
No & USC-42 & 2.6964 & $2.9344^{* *}$ & 0.9691 & 0.8190 & 2.6130 & $2.5498^{* *}$ \\
No & UPAM-43 & 0.3163 & $0.3351^{* *}$ & 0.8659 & 0.7727 & 0.2739 & $0.2722^{* *}$ \\
No & UPAM-50 & 0.7734 & 0.8461 & 0.8565 & $0.7331^{* *}$ & 0.6624 & $0.6522^{* *}$ \\
No & USC-51 & 1.3346 & 1.4774 & 0.8783 & 0.7472 & 1.1721 & $1.1800^{* *}$ \\
No & UPAM-55 & 0.3873 & $0.4265^{* *}$ & 0.8549 & $0.7326^{* *}$ & 0.3311 & $0.3311^{* *}$ \\
No & UPAM-59 & 1.5407 & $1.5880^{* *}$ & 0.9012 & 0.7943 & 1.3884 & 1.3007 \\
No & USC-64 & 1.5187 & 1.6225 & 0.8604 & 0.7357 & 1.3067 & 1.2582 \\
No & USC-65 & 0.6730 & $0.6975^{* *}$ & 0.9234 & 0.8080 & 0.6215 & $0.5855^{* *}$ \\
No & USC-68 & 0.7268 & $0.7412^{* *}$ & 0.9955 & 0.8866 & 0.7236 & $0.6809^{* *}$ \\
No & USC-69 & 0.8956 & 0.9304 & 0.8896 & 0.7280 & 0.7967 & $0.7192^{* *}$ \\
Geom.Mean-all & & 0.9048 & 0.9772 & 0.8913 & 0.7693 & 0.8064 & 0.7924 \\
Geom.Mean-subset & & 0.8178 & 0.8722 & 0.8478 & 0.7200 & 0.7411 & 0.7236 \\
Improvement & & & 7 & & 5 & & 12 \\
No change & & 9 & & 15 & & 4 \\
Decline & & 4 & & 0 & & 4 \\
\hline
\end{tabular}

EC= Efficiency Change, TC=Technical Change, M=Malmquist index. BC-=Bias-Corrected. ${ }^{* *}$ statistically significant at 5\%. Notes: Geom.Mean-all is calculated as the mean of changes associated to the entire sample whereas Geom.Mean-subset is calculated as the mean of only statistically significant changes. Improvement, No change and Decline indicate the number of TTOs which experienced statistically significant progress, any significant change, and statistically significant regress, respectively. 
Figures of the paper

Figure 1: Boxplot of TTO's efficiency changes, technological change and Malmquist Index by university category and presence of a hospital. TTOs without hospital are represented in blue and TTOs with hospital in green.
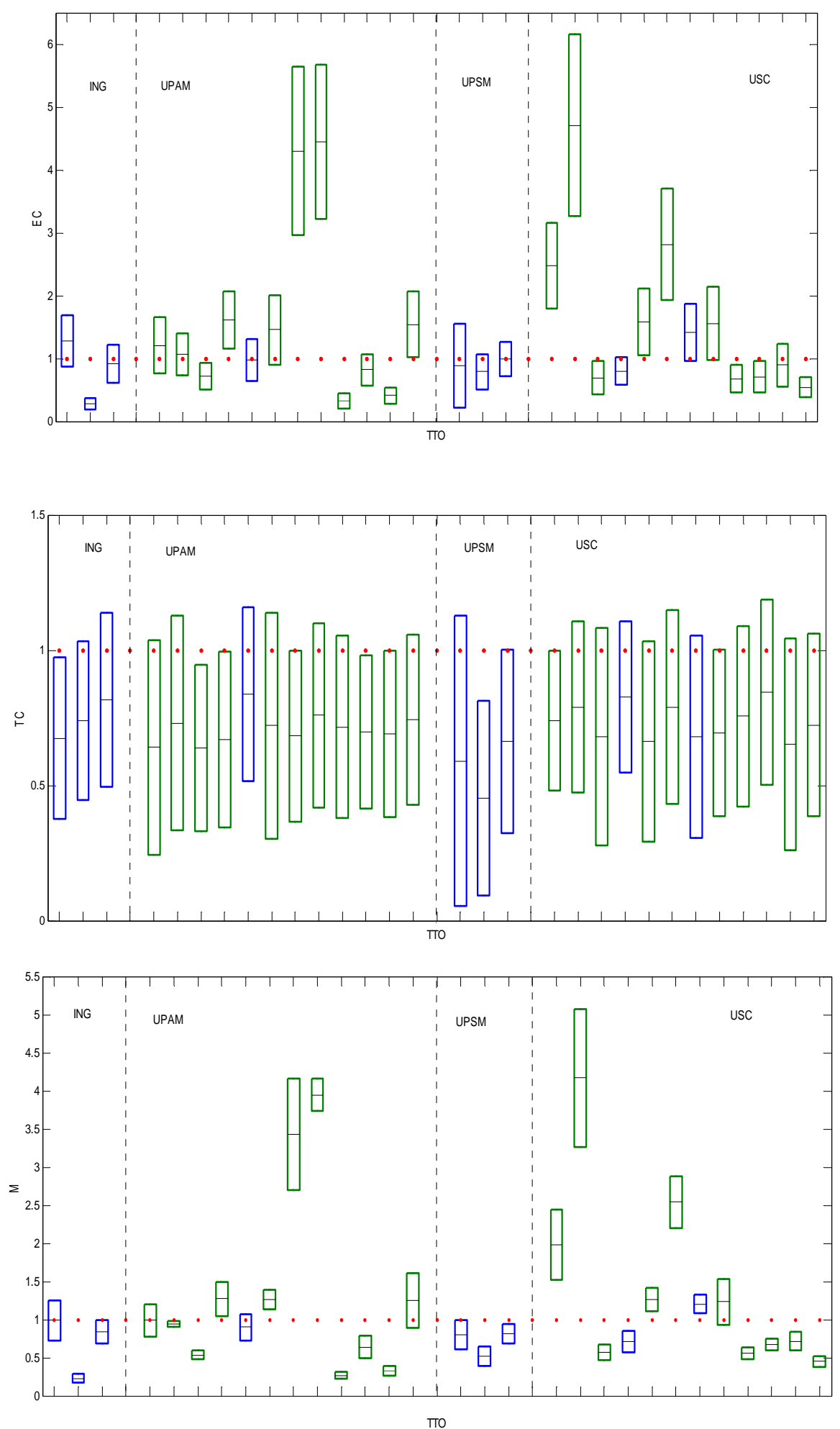
Figure 2: Boxplot of TTO's efficiency changes, technological change and Malmquist Index by university category and seniority. Mature TTOs are represented in blue and young TTOs in green.
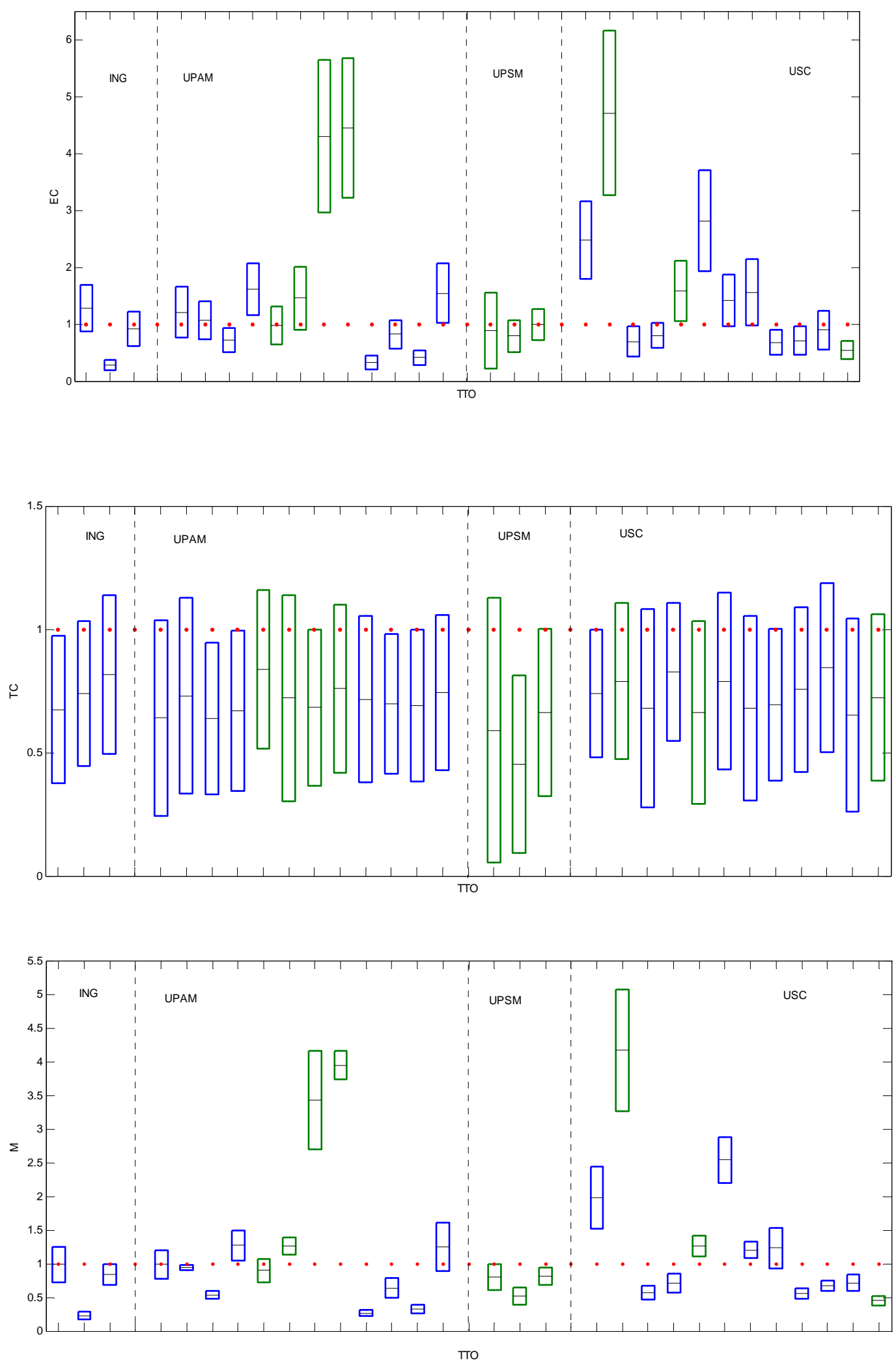